Marcia Kikuyo Notomi ${ }^{1}$ Marcia Mery KOGIKA ${ }^{1}$ Júlia Yuzuki Habu IKESAKI² Paula Rumy Gonçalves MONTEIRO $^{2}$

Maurício Luís MARQUESI²

\section{Correspondência para:}

MARCIA KIKUYONOTOMI

Departamento de Clínica Médica

Faculdade de Medicina Veterinária e

Zootecnia

Universidade de São Paulo

Av. Prof. Dr. Orlando Marques de Paiva, 87

Cidade Universitária Armando de Salles

Oliveira

05508-000 - São Paulo - SP

mnotomi@usp.br

mnotomi@hotmail.com

Recebido para publicação: 15/12/2003 Aprovado para publicação: 12/12/2006

\title{
Estudo retrospectivo de casos de insuficiência renal crônica em cães no período de 1999 a 2002
}

\author{
1 - Departamento de Clínica Médica da Faculdade de Medicina Veterinária e \\ Zootecnia da Universidade de São Paulo, São Paulo - SP \\ 2 - Hospital Veterinário da Faculdade de Medicina Veterinária e Zootecnia \\ da Universidade de São Paulo, São Paulo - SP
}

\section{Resumo}

Com o objetivo de compilar e salientar as informações provenientes do histórico clínico, alterações nos exames laboratoriais e no exame ultra-sonográfico que permitam traçar o perfil clínico dos pacientes, procedeu-se ao estudo retrospectivo de 191 casos de insuficiência renal crônica (IRC) em cães atendidos no período de 3 anos no HOVET/ FMVZ - USP. Foram incluídos aqueles que apresentavam concentração sangüínea de uréia $>40 \mathrm{mg} / \mathrm{dL}$ e de creatinina $>2 \mathrm{mg} / \mathrm{dL}$. A maioria dos cães tinha idade superior a 7 anos e, entre os cães de raça definida, a raça mais representada foi o Cocker Spaniel, tanto entre os jovens quanto entre os animais de idade mais avançada. Alterações no apetite, êmese, apatia e poliúria/polidipsia foram as principais manifestações clínicas relatadas. Anemia do tipo não regenerativa e hiperfosfatemia foram as alterações mais freqüentes, além daquelas observadas constatadas no exame de urina (densidade urinária baixa, proteinúria e cilindrúria ausente ou em pequena quantidade). As alterações detectadas no exame ultra-sonográfico renal (aumento de ecogenicidade, redução do tamanho, contorno irregular e a diminuição ou ausência do limite córtico-medular) podem trazer informações adicionais para o diagnóstico de nefropatia crônica em cães.

\section{Introdução}

A insuficiência renal crônica (IRC) é uma importante causa de morbidade e mortalidade nos cães ${ }^{1,2}$, e se caracteriza por um curso progressivo, sendo o processo inicial desencadeante difícil de ser estabelecido na maioria dos casos. Ocorre principalmente nos animais de idade mais avançada ${ }^{3}$ tanto em cães ${ }^{4}$ quanto em gatos ${ }^{5,6,7}$. É também observada em animais mais jovens, associada a doenças renais congênitas ou hereditárias, sendo mais freqüente em cães de raça definida ${ }^{8,9,10}$. Ambos os sexos são igualmente acometidos, tanto na forma juvenil como na forma senil ${ }^{11}$.

A alteração funcional do rim ocorre quando há perda de mais de $66 \%$ a 75\% dos néfrons, comprometendo a manutenção dos equilíbrios hidroletrolítico e ácido- básico e da capacidade de excreção de produtos resultantes do metabolismo, além de interferir na síntese de várias substâncias ${ }^{12,13}$.

O gradual aumento da disfunção renal compromete também a capacidade funcional de outros órgãos, resultando no aparecimento da síndrome urêmica ${ }^{14}$. No decorrer da evolução da IRC e na dependência do grau de comprometimento renal, observa-se o comprometimento de outros sistemas orgânicos tais como o digestivo $^{14,15}$, cardiovascular ${ }^{16}$, esquelético ${ }^{17,18,19}$, neurológico ${ }^{13,20}$ e hematopoético ${ }^{21,22}$, entre outros. As manifestações clínicas ocorrem isoladamente ou em conjunto ${ }^{14}$. Os sintomas inicialmente observados pelos proprietários de cães estão relacionados à diminuição da capacidade de concentrar a urina ${ }^{12}$, refletindo a perda de parte considerável da capacidade 
funcional dos rins ${ }^{13}$.

$\mathrm{Na}$ maioria das vezes os pacientes caninos são submetidos à avaliação clínica quando a doença renal se encontra em estágio final de evolução e a síndrome urêmica já se encontra instalada e nessas condições, o prognóstico é reservado.

O reconhecimento das principais manifestações clínicas e das alterações laboratoriais que ocorrem no decurso da IRC pode trazer subsídios para o auxílio no diagnóstico da IRC. Os trabalhos de Di Bartola et al. ${ }^{5}$ e Elliot e Barber ${ }^{6}$ trouxeram informações preciosas para o reconhecimento da IRC em gatos, já em relação aos cães, os trabalhos existentes são pouco recentes ${ }^{4,23}$, embora os aspectos clínicos da IRA tenham sido analisados por Vander, Levine e Breitswerdt ${ }^{24}$.

Com o objetivo de compilar e salientar as informações pertinentes ao histórico clínico, alterações nos exames laboratoriais e no exame ultra-sonográfico que permitam traçar o perfil clínico dos pacientes com IRC, procedeu-se ao estudo retrospectivo dos casos de IRC em cães.

\section{Materiais e Métodos}

Foram incluídos no estudo os cães com insuficiência renal crônica (IRC) atendidos no Serviço de Clínica Médica de Pequenos Animais - VCM/HOVETFMVZ/USP no período de agosto de 1999 a julho de 2002, totalizando 191 casos.

Utilizou-se como critério de inclusão a persistência das concentrações séricas de uréia superiores a $40 \mathrm{mg} / \mathrm{dL}$ e as de creatinina acima de $2,0 \mathrm{mg} / \mathrm{dL}$, por um período mínimo de 15 dias e como critério de exclusão, a existência de outras enfermidades concomitantes, clinicamente detectadas. Foram analisadas as distribuições quanto à definição racial e faixa etária, as informações obtidas na anamnese, nos parâmetros hematológicos e bioquímicos (cálcio, fósforo, sódio, potássio, albumina e fosfatase alcalina) e no exame de urina (densidade, $\mathrm{pH}$, proteinúria, presença de cilíndros). As alterações observadas no exame ultra-sonográfico foram também compiladas. Nem todos os exames realizados no mesmo paciente foram incluídos no estudo, considerando-se apenas os exames realizados no primeiro atendimento. Assim, para cada variável analisada, foi considerado o $\mathbf{n}$ disponível para o parâmetro em questão. Os exames hematológicos e bioquímicos foram realizados no Laboratório Clínico do HOVET/ Departamento de Clínica Médica, da FMVZ-USP de acordo com as técnicas rotineiras, utilizando-se equipamentos automatizados (ABC vet-ABX Diagnostics, França e Analisador Bioquímico modelo Lyasis- American Medical System, Itália) e o exame ultra-sonográfico foi realizado no Serviço de Diagnóstico por Imagem do VCI/HOVET -FMVZ/USP, utilizando-se o equipamento CS3030 (TOKIMEC) com transdutores linear de $7,5 \mathrm{mHz}$ e convexo de $5,9 \mathrm{mHz}$.

As variáveis estudadas foram agrupadas e analisadas de acordo com os preceitos de estatística descritiva ${ }^{25}$.

\section{Resultados}

A distribuição dos casos de IRC, de acordo com a faixa etária, encontra-se apresentada na figura 1; a condição mórbida foi observada principalmente em animais de faixa etária superior ( $>7$ anos). Entretanto, também foi observada a forma congênita da IRC, principalmente em cães de raça definida, com predominância da raça Cocker Spaniel Inglês. Os cães dessa raça também se encontravam representados em maior número, entre os casos de IRC adquirida. Outras raças de cães, bem como os cães sem definição racial também se encontravam presentes com a condição mórbida em questão, conforme se verifica na tabela 1 .

Os casos de IRC foram distribuídos de maneira uniforme por todo o período de estudo, com cerca de 30 casos por semestre. Ambos os sexos são igualmente acometidos, já que os machos se constituíram 
Tabela 1 - Distribuição dos cães com insuficiência renal crônica $(n=191)$ atendidos no Serviço de Clínica Médica de Pequenos Animais do VCM/ HOVET da FMVZ/USP, no período de agosto de 1999 a julho de 2002, segundo a definição racial. São Paulo, 2003

\begin{tabular}{lc}
\hline \multicolumn{1}{c}{ Definição racial } & $\mathrm{n}^{\circ}$ por raça / frequência (\%) \\
\hline SEM DEFINIÇÃO RACIAL (SDR)) & $59(30,89 \%)$ \\
COM DEFINIÇÃO RACIAL & $122(69,11 \%)$ \\
- Cocker Spaniel Inglês & $28(14,66 \%)$ \\
- Poodle & $22(11,52 \%)$ \\
- Pastor Alemão & $14(7,33 \%)$ \\
- $\quad$ Lhasa Apso, Terrier Brasileiro & $6(3,14 \%)$ \\
- Pinsher & $5(2,62 \%)$ \\
- Dogue Alemão, Husky Siberiano & $4(2,09 \%)$ \\
- Boxer, Dálmata, Dobberman Pinsher, Pequinês, & \\
$\quad$ Rottweiller, Schnauzer, Sheepdog, Shitzu, & $3(1,57 \%)$ \\
$\quad$ Weimaraner, Yorkshire & $2(1,05 \%)$ \\
- Fila Brasileiro & \\
Airedale Terrier, Beagle, Collie, Teckel, Labradbr & Retriever, Lulu, Maltes, Pastor Shettland, Setter \\
$\quad$ Irlandes, Sharpei, Springer Spaniel & $10,05 \%)$ \\
\hline TOTAL & $191(100 \%)$ \\
\hline
\end{tabular}

Tabela 2 - Freqüências absoluta e relativa dos sintomas observados pelos proprietários em cães com insuficiência renal crônica, atendidos no Serviço de Clínica Médica de Pequenos Animais do VCMHOVET da FMVZ/USP, no período de agosto de 1999 a julho de 2002 . São Paulo, 2003

\begin{tabular}{lcc}
\hline Sintoma & $\mathrm{n}^{\circ}$ de citações/ $\mathrm{n}^{\circ}$ de resposta & Freqüência relativa (\%) \\
\hline Disorexia / anorexia & $159 / 191$ & $83 \%$ \\
Êmese & $134 / 191$ & $70 \%$ \\
Apatia & $130 / 186$ & $70 \%$ \\
Poliúria/polidipsia & $96 / 186$ & $52 \%$ \\
Alteração na coloração e & $69 / 185$ & $37 \%$ \\
consistência das fezes & $49 / 130$ & $38 \%$ \\
Emagrecimento & & \\
\hline
\end{tabular}

em $55 \%$ dos casos e as fêmeas em $45 \%$.

As manifestações clínicas relatadas na anamnese e que foram observadas pelos proprietários estão apresentadas na tabela 2; anorexia/ disorexia, êmese, poliúria e polidipsia foram as principais alterações clínicas observadas.

Os valores observados nas variáveis do eritrograma e do leucograma estão apresentados na tabela 3; observa-se anemia não regenerativa na maioria dos cães com IRC. Encontram-se dispostos, na figura 2, os valores das concentrações séricas de fósforo, cálcio, sódio, potássio, albumina e fosfatase alcalina; as principais alterações foram constatadas em relação as concentrações séricas de fósforo inorgânico e potássio que apresentaram valores aumentados.

Em relação à freqüência das alterações observadas no exame de urina, encontra-se apresentada na figura 3; acidúria, proteinúria ausente ou de intensidade discreta, cilindrúria ausente ou em pequena quantidade e valores de densidade urinária baixa foram as principais alterações detectadas.

Quando se cotejou a informação prestada pelo proprietário em relação ao volume urinário e a ingestão de água (PU/ PD), considerados os sintomas iniciais mais indicativos da perda da capacidade renal de concentração da urina, com a densidade 
Tabela 3 - Variáveis do hemograma em cães com insuficiência renal crônica $(n=154)$ atendidos no Serviço de Clínica Médica de Pequenos Animais do VCMHOVET na FMVZ/USP e valor médio, erro padrão da média (EPM) e freqüência de valores situados acima ou abaixo dos valores de referência. São Paulo 2003

\begin{tabular}{lcccc}
\hline \multicolumn{1}{c}{ Variáveis } & Média $\pm \mathrm{EPM}$ & $\begin{array}{c}\text { valores superiores } \\
(\%)\end{array}$ & $\begin{array}{c}\text { valores inferiores }(\%) \\
\text { intervalo de } \\
\text { referência* }\end{array}$ \\
\hline Hemácias $\left(10^{6} / \mu \mathrm{L}\right)$ & $4,27 \pm 0,14$ & $1(0,6 \%)$ & $105(68 \%)$ & $5,0-8,0$ \\
Hematócrito $(\%)$ & $29,25 \pm 0,91$ & $2(1,3 \%)$ & $117(76 \%)$ & $37-54$ \\
$\begin{array}{l}\text { Hemoglobina } \\
(\mathrm{g} / \mathrm{dL})\end{array}$ & $9,77 \pm 0,30$ & $2(1,3 \%)$ & $116(75 \%)$ & $12-18$ \\
VCM (fl) & $69,40 \pm 0,49$ & $12(7,8 \%)$ & $2(1,3 \%)$ & $60-77$ \\
$\mathrm{CHCM}(\%)$ & $33,38 \pm 1,71$ & $6(3,9 \%)$ & $13(8,4 \%)$ & $31-36$ \\
$\begin{array}{l}\text { Leucócitos } \\
\left(10^{3} / \mu \mathrm{L}\right)\end{array}$ & $14168 \pm 682,7$ & $52(33,8 \%)$ & $12(7,8 \%)$ & $6.000-15.000$ \\
$\begin{array}{l}\text { Segmentados } \\
\left(10^{3} / \mu \mathrm{L}\right)\end{array}$ & $11677 \pm 629,9$ & $56(36,4 \%)$ & $1(0,6 \%)$ & $3-11.800$ \\
$\begin{array}{l}\text { Eosinófilos } \\
\left(10^{3} / \mu \mathrm{L}\right)\end{array}$ & $395 \pm 52,3$ & $22(14,3 \%)$ & - & $0-750$ \\
$\begin{array}{l}\text { Linfócitos }\left(10^{3} / \mu \mathrm{L}\right) \\
\text { Monócitos }\end{array}$ & $1283 \pm 134$ & $4(3 \%)$ & $121(79 \%)$ & $1.500-5.000$ \\
$\left(10^{3} / \mu \mathrm{L}\right)$ & $895 \pm 90,6$ & $53(34,4 \%)$ & - & $0-800$ \\
Reticulócitos $(\%)^{2}$ & $0,16 \pm 0,024$ & $0(0 \%)$ & $69(100 \%)$ & $1 \%$ \\
\hline
\end{tabular}

Tabela 4 - Característica ultra-sonográfica observada no parênquima renal dos cães com insuficiência renal crônica, atendidos no Serviço de Clínica Médica de Pequenos Animais do VCM/HOVET daFMVZ/USP, no período de agosto de 1999 a julho de 2002. São Paulo 2003

\begin{tabular}{|c|c|c|c|}
\hline VARIÁVEIS & CARACTERÍSTICA & $\begin{array}{c}\text { Rim Direito } \\
\mathrm{n}^{\circ} \text { de animais (\%) }\end{array}$ & $\begin{array}{c}\text { Rim esquerdo } \\
\mathrm{n}^{\circ} \text { de animais (\%) }\end{array}$ \\
\hline \multirow{3}{*}{ Tamanho } & normal & $68(54 \%)$ & $66(53 \%)$ \\
\hline & aumentado & $2(2 \%)$ & $3(2 \%)$ \\
\hline & diminuído & $56(44 \%)$ & $56(45 \%)$ \\
\hline \multirow{2}{*}{ Contorno } & regular & $39(31 \%)$ & $41(33 \%)$ \\
\hline & irregular & $87(69 \%)$ & $84(67 \%)$ \\
\hline \multirow{3}{*}{ Ecogenicidade } & normal & $15(12 \%)$ & $16(13 \%)$ \\
\hline & aumentado & $111(88 \%)$ & $109(87 \%)$ \\
\hline & diminuído & $0(0 \%)$ & $0(0 \%)$ \\
\hline \multirow{3}{*}{$\begin{array}{l}\text { Definição de limite } \\
\text { córtico-medular }\end{array}$} & presente & $18(14 \%)$ & $15(12 \%)$ \\
\hline & diminuído & $64(51 \%)$ & $67(54 \%)$ \\
\hline & ausente & $44(35 \%)$ & $43(34 \%)$ \\
\hline
\end{tabular}

urinária, observou-se que a PU/PD foi relatada em $60 \%$ dos casos em que a densidade urinária era menor do que 1,015 e em $53,3 \%$ dos casos em que a densidade urinária se encontrava entre 1,016 e 1,030.

A avaliação ultra-sonográfica dos rins foi realizada em 129 dos cães com IRC. As alterações relativas ao tamanho, ecogenicidade e definição de limite córtico-medular estão mencionadas na tabela 4. As principais alterações ultra-sonográficas observadas no parênquima renal foram o aumento da ecogenicidade, contorno irregular dos rins, diminuição ou ausência da definição do limite 


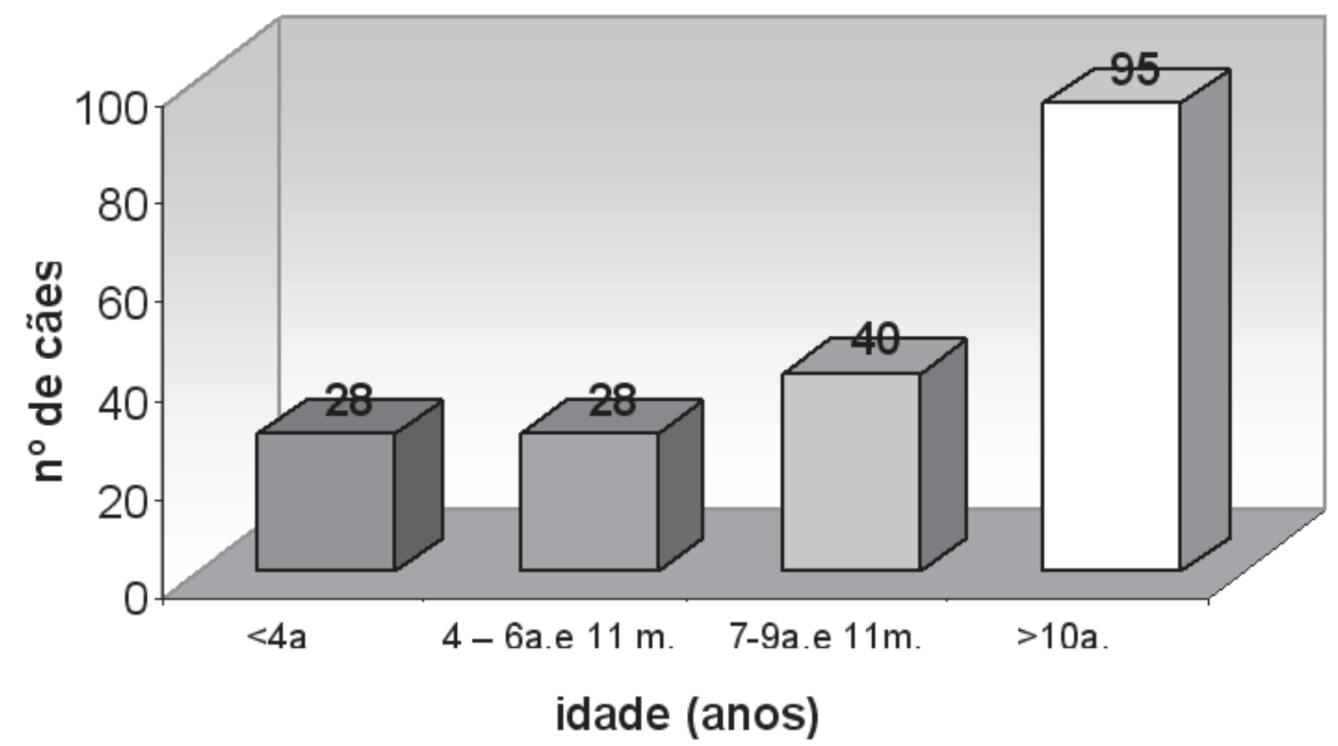

Figura 1 - Distribuição dos casos de insuficiência renal crônica em cães $(n=191)$, atendidos no Serviço de Clínica Médica de Pequenos Animais do VCM/HOVET da FMVZ/USP, no período de agosto de 1999 a julho de 2002, segundo a faixa etária. São Paulo, 2003

córtico-medular e diminuição de tamanho. Ainda, o exame ultra-sonográfico permitiu identificar presença de cisto renal $(\mathrm{n}=8)$, hipoplasia renal $(\mathrm{n}=6)$, sinal medular $(\mathrm{n}=5)$, litíase $(n=4)$ e agenesia renal unilateral $(n=2)$.

\section{Discussão}

A maior freqüência dos casos de IRC entre os cães de faixa etária maior, à semelhança das observações de Cowgill e Spangler ${ }^{4}$, Richards e $\mathrm{Hoe}^{23}$, DiBartola et al. ${ }^{5}$, Elliot e Barber ${ }^{6}$ e Lulich et al. ${ }^{26}$ pode ser facilmente justificada pela fisiopatologia da IRC $^{3}$. Trata-se de uma condição mórbida de instalação insidiosa, lentamente progressiva e que ocorre como resultado de doença renal adquirida ${ }^{14}$ ou congênita ${ }^{27}$. No primeiro caso, a IRC é observada em animais mais velhos, enquanto a forma congênita ou familial é encontrada em cães adultos jovens, de até cinco anos de idade ${ }^{8,9}$. Certas raças de cães parecem apresentar maior predisposição ao desenvolvimento de IRC de origem congênita, citando-se entre elas Basenji, Beagle, Bull Terrier, Chow Chow, Cocker Spaniel, Dobberman, Lhasa Apso, Poodle Standard, Rottweiller, Sharpei e Shitzu ${ }^{8,10,27}$. Na amostragem estudada, cães da raça Cocker Spaniel foram encontrados em maior número, tanto nos animais de faixa etária inferior a cinco anos, quanto nos de idade mais avançada, o que indica uma provável predisposição dos cães dessa raça em particular, ao desenvolvimento de doenças renais e da IRC. O primeiro relato de doença familial renal foi a displasia renal, reconhecida na raça Cocker Spaniel ${ }^{7,27}$. Não existe aparentemente uma predisposição sexual, conforme já havia sido observado por ADAMS.

As manifestações clínicas relatadas na anamnese, como as alterações do apetite, êmese e modificação na consistência e coloração das fezes refletem o comprometimento do sistema digestivo. As toxinas urêmicas, atuando diretamente no centro do vômito ${ }^{28}$, a gastrite e as ulcerações gástricas, freqüentes nos casos mais avançados de IRC se encontram na gênese dos distúrbios gastrentéricos e que, por seu turno, podem conduzir ao "emagrecimento", relatado pelos proprietários.

A poliúria e polidipsia (PU/PD) relatadas em $52 \%$ dos casos são freqüentemente descritas durante a evolução da IRC, particularmente entre os cães ${ }^{1,12,14}$, 


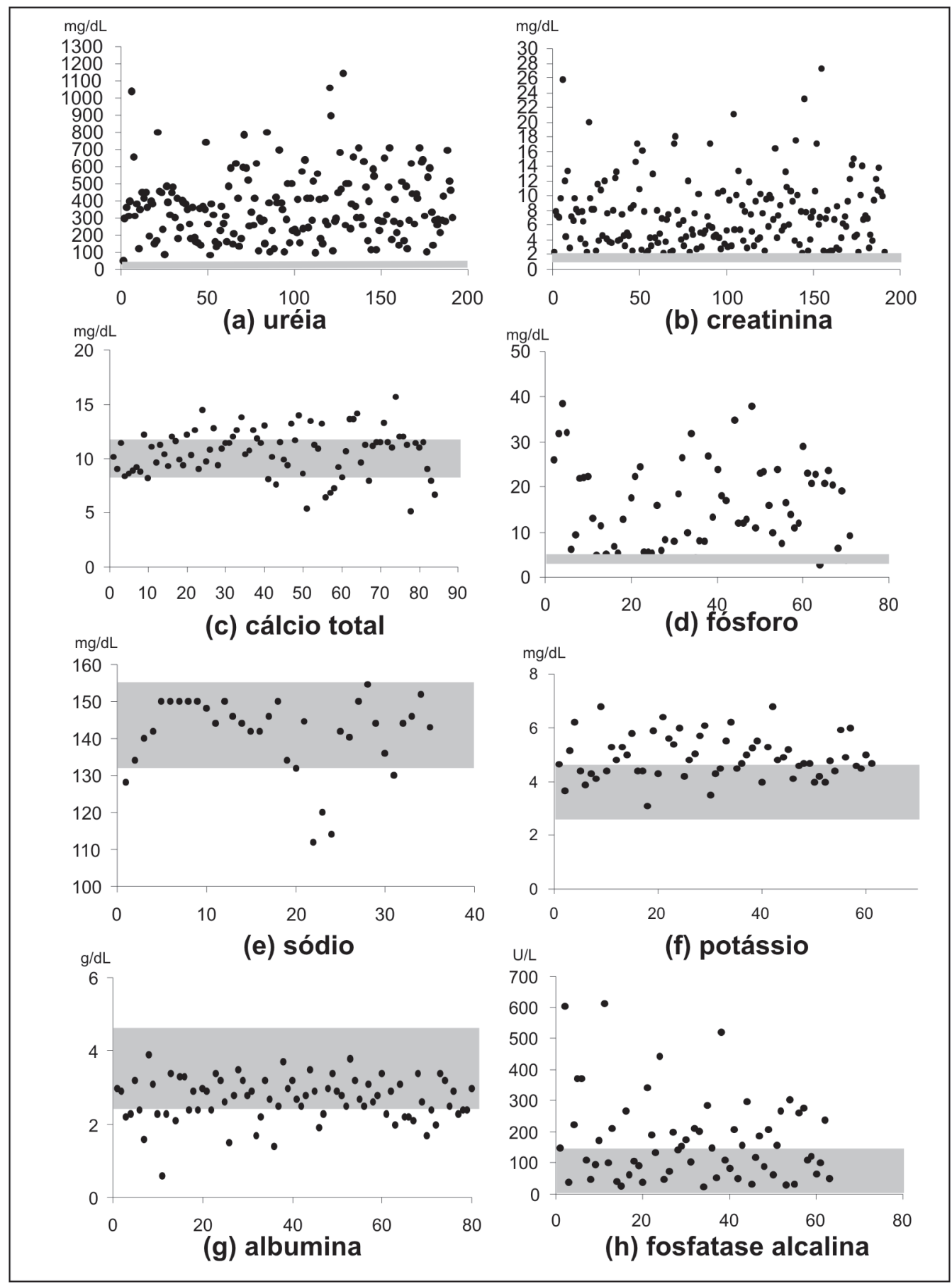

Figura 2 - Distribuição dos valores séricos de (a) uréia (mg/dL), (b) creatinina (mg/dL), (c) cálcio total (mg/dL), (d) fósforo (mg/dL), (e) sódio (mg/dL), (f) potássio (mg/dL), (g) albumina (g/dL) e (h) fosfatase alcalina (U/L) em cães com linsuficiência renal crônica atendidos no Serviço de Clínica Médica de Pequenos Animais do VCM/HOVET na FMVZ/USP. São Paulo, 2003 


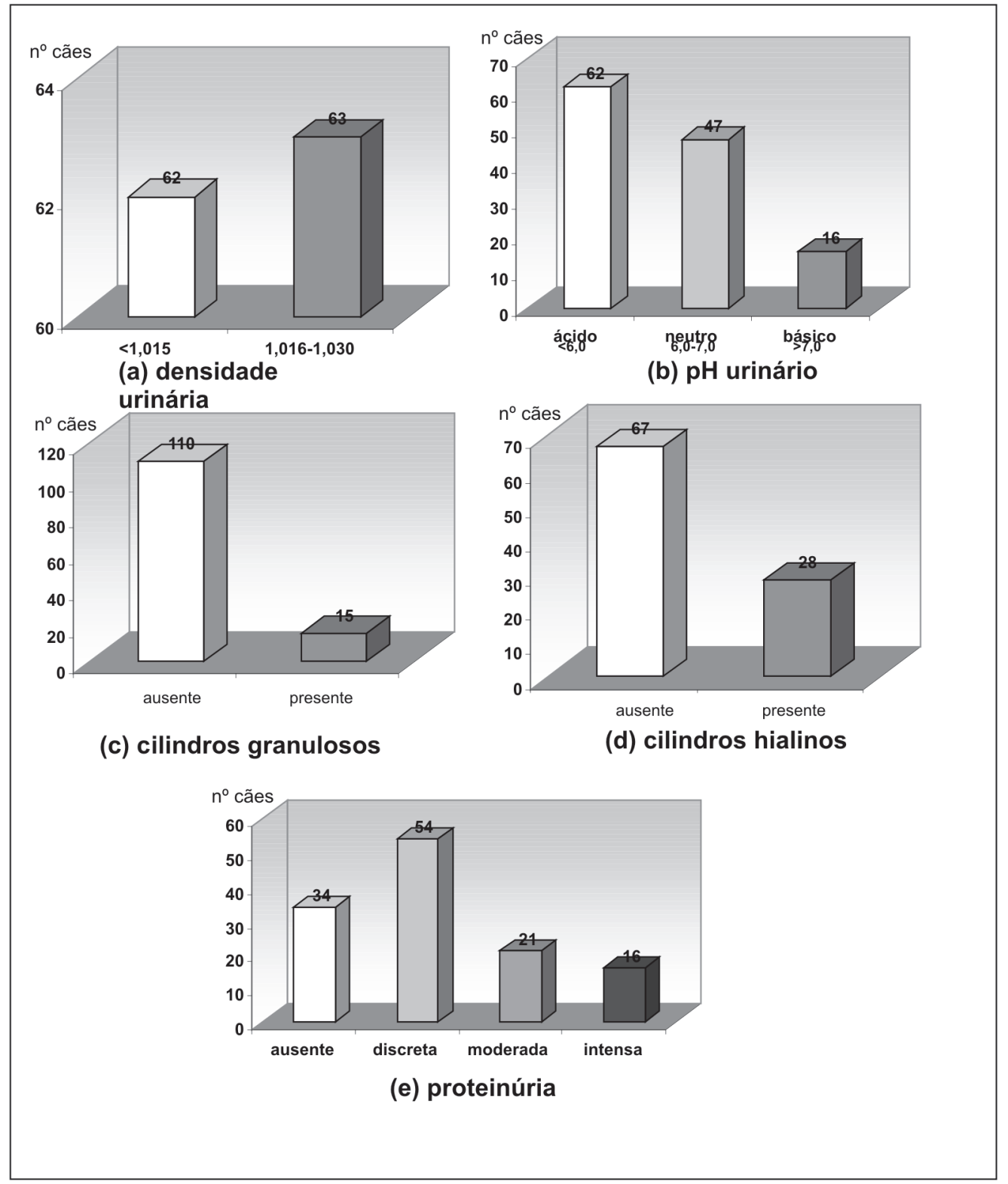

Figura 3 - Distribuição dos cães com insuficiência renal crônica $(n=125)$, atendidos no Serviço de Clínica Médica de Pequenos Animais do VCM HOVET na FMVZ/ USP, no período de agosto de 1999 a julho de 2002, em relação as variáveis do exame de urina: (a) densidade

urinária, (b) pH urinário, (c) presença de cilindros granulosos, (d) presença de cilindros hialinos e (e) presença de proteína. São Paulo, 2003

que diferem dos felinos nesse aspecto ${ }^{6,17}$. A incapacidade de concentração da urina precede o comprometimento da taxa de filtração glomerular e é clinicamente observável quando há comprometimento de cerca de $66 \%$ dos néfrons ${ }^{29}$.

Aparentemente não houve uma relação direta entre a PU/PD relatadas e a densidade urinária, mensurada nas amostras de urina, já que nos cães com isostenúria (densidade urinária igual ou inferior a 1,015) em apenas $60,6 \%$ dos casos havia sido observada alteração na micção ou na ingestão de água em proporção semelhante naqueles casos em que a densidade urinária se situava entre 1,016 e 1,030. 
Proteinúria ausente ou discreta, bem como a ausência de cilindros hialinos ou granulosos na maioria dos casos, indicaram a inexistência de doença renal ativa, ou, se existente, de mínimo grau, sendo a IRC conseqüência da perda gradativa de néfrons $^{30}$. $\mathrm{O} \mathrm{pH}$ urinário ácido $(\mathrm{pH} 5,5)$ observado em cerca de metade das análises urinárias realizadas, pode estar refletindo o mecanismo compensatório renal, na tentativa de manter o equilíbrio ácido - base do organismo ${ }^{30}$. A função dos néfrons remanescentes encontra-se intensificada na IRC, na tentativa de compensar os néfrons perdidos com a progressão da doença ${ }^{31}$.

Nos animais com IRC a anemia, observada em cerca de dois terços dos cães estudados, é uma observação clínica freqüente $^{32}$ e resulta, na maioria das vezes, em conseqüência do comprometimento da síntese de eritropoetina ${ }^{32,33}$. O caráter não regenerativo da anemia foi comprovado pela quantificação de reticulócitos. Outros mecanismos, entre eles, a inibição da eritropoese pela ação do hormônio paratireoidiano também podem estar envolvidos na gênese da anemia $^{34}$. Embora o PTH não tenha sido especificamente mensurado, o aumento das concentrações séricas de fósforo $(83 \%$ dos casos) e da atividade sérica de fosfatase alcalina sugerem indiretamente a ocorrência de hiperparatireoidismo secundário ${ }^{35}$. As variações nas concentrações séricas de cálcio também relatadas na literatura ${ }^{36}$ refletem a instabilidade da homeostase de cálcio e fósforo ${ }^{21,37,38}$.

A grande variabilidade na freqüência e intensidade das variáveis analisadas pode ser creditada as próprias características da IRC, de início insidiosa e lentamente progressiva e de longa duração. Assim, tendo como critério de inclusão a manutenção da concentração sérica de uréia e de creatinina em patamares que excedem o intervalo de referência para a espécie ${ }^{39}$, os cães incluídos no estudo apresentavam valores de creatinina que variaram de $2,18 \mathrm{mg} / \mathrm{dL}$ a $27,30 \mathrm{mg} /$ dL. Considerando que existe um aumento da concentração sérica de creatinina à medida que ocorre a progressão da IRC é possível afirmar que no grupo analisado havia animais com diferentes graus de IRC.

A hiperfosfatemia reflete o comprometimento da excreção renal do fósforo que ocorre precocemente, antes mesmo de ocorrer à perda de três quartos da capacidade funcional dos néfrons ${ }^{40}$. Assim, sua mensuração assume importância na monitorização da doença, principalmente considerando-se o fato de que quando o valor da multiplicação das concentrações séricas de ambos os íons (cálcio e fósforo) ultrapassa 60, existe o risco de calcificação metastática e deposição de sais de cálcio, inclusive no parênquima renal, agravando ainda mais o funcionamento do órgão ${ }^{31}$.

A hiperpotassemia ou a hipopotassemia, assim como a hiponatremia observadas numa parcela dos casos estudados são encontradas em cães ou gatos com IRC ${ }^{5,6,41}$, refletindo ora a alteração na excreção de eletrólitos ou a acidose, resultando na hiperpotassemia, ora alteração na homeostase hídrica, que pode ser acompanhada da hipopotassemia ${ }^{42}$. O depauperamento orgânico nos casos mais avançados de IRC, a desnutrição calórica protéica dos pacientes com distúrbios digestivos e o estresse crônico resultante da contínua liberação de $\operatorname{cortisol}^{43}$ justificam a hipoalbuminemia e o leucograma de estresse (neutrofilia, com neutrófilos maduros e linfopenia) encontrados em parte dos pacientes, não estando intrinsecamente relacionados à evolução da IRC.

As diferentes alterações da imagem renal, reveladas pelo exame ultrasonográfico, como a diminuição do tamanho, irregularidade dos contornos ou o aumento da ecogenicidade do parênquima e a pouca definição do limite córticomedular referem-se a alterações na morfologia renal, não se correlacionando com a função do órgão ${ }^{44}$. Entretanto, o exame ultra-sonográfico pode revelar a presença de alterações no parênquima renal, tais como agenesia unilateral, hipoplasia, cisto e litíase que poderiam ter contribuído para o desenvolvimento da IRC. 


\section{Conclusões}

nos animais idosos

- em cães, a IRC ocorre principalmente

- a IRC em cães jovens e idosos ocorreu principalmente nos animais com raça definida;

- a determinação da concentração sérica de fósforo inorgânico, a definição do tipo de anemia e os dados do exame de urina podem fornecer subsídios para o diagnóstico da IRC;

a avaliação ultra-sonográfica dos rins pode trazer informações adicionais para o diagnóstico da nefropatia crônica;

\title{
Retrospective study of chronic renal failure cases in dogs between 1999 a 2002
}

\begin{abstract}
During the period of three years, a retrospective study of 191 dogs with chronic renal failure was performed, in order to describe and focus information concerning history and clinical signs, as well as laboratorial and ultrasound findings, that could help for better understanding of the disease. Dogs included in this study had presented serum concentration levels of urea and creatinin above $40 \mathrm{mg} / \mathrm{dL}$ and $2 \mathrm{mg} / \mathrm{dL}$, respectively. Most of the animals were older than 7 year-old, and Cocker Spaniel was the main breed observed among young and old affected dogs. Reduction of appetite, vomiting, lethargy, polidipsia and poliuria were the main clinical signs detected. Non-regenerative anemia and hyperphosphatemia, as well as urinalysis (low urinary specific gravity, absent or slight amount of proteinuria and casts in urinary sediment) and ultrasound exam findings (increase in ecogenicity, decrease in size, irregular shape to the renal contour and narrow toward the corticomedullary junction) could help to additional information for the diagnosis of chronic nephropathy in dogs.
\end{abstract}

Key-words: Chronic renal failure.

\section{Referências}

1 BROWN, S. A. et al. Pathophysiology and Management of Progressive Renal Disease The Veterinary Journal, n. 154, p. 93-109, 1997.

2 KRAWIEC, D. R.; ITKIN, R. J. When and How to Measure Glomerular Filtraton rate and Effective Renal Plasma Flow. In: KIRK'S current veterinary therapy XII., 12a ed., Philadelphia: W.B.Saunders, 1995. p. 931-933.

3 ALLEN, T. A.; ROUDEBUSH, P. Canine Geriatric Nephrology Compendium Continuing Education Practicing, v. 12, n. 7, p. 909-917, 1990.

4 COWGILL, L. D.; SPANGLER, W. L. Renal Insufficiency in geriatric dogs. Veterinary Clinics of North America. Small Animal Medicine, v. 11, n. 4 , p. $727-748,1981$.

5 DIBARTOLA, S. P. et al. Clinicopathologic findings associated with chronic renal disease in cats: 74 cases (1973-1984). Journal of Veterinary Medical Association, v. 190, n. 9, p. 1196-1202, 1987.

6 ELLIOT, J.; BARBER, P. J. Feline chronic renal failure: clinical findings in 80 cases diagnosed between 1992 and 1995. Journal of Small Animal Practice, v. 39, n. 2, p. 78-85, 1998.

7 LEES, G. E. et al. Glomerular Ultrastructural findings similar to hereditary nephritis in 4 english cocker spaniel. J. Vet Int Med, v. 11, n. 2, 1997. p. 80-85, 1997.

8 COELHO, B. M. P. et al. Insuficiência Renal crônica em cães jovens: estudo clínico de 25 casos. Revista Clínica Veterinária, n. 33, p. 52-56, 2001.

9 DE MORAIS, H. S.; DIBARTOLA, S. P.; CHEW, D. J. Juvenile renal disease in Golden Retrievers: 12 cases (1984-1994) JAVMA, v. 209, n. 4, 1996.

10 LEES, G. E. Congenital Renal Disease - Renal dysfunction Veterinary Clinics of North America: Small Animal Practice v. 26, n. 6, p. 1379-1399, 1996.

11 ADAMS, L. G. Falla Renal Cronica - Enfermidades y Sindromes Clinicos In: THE 5 minutes veterinary consult. Baltimore: Willians \& Wilkins, 1997. p. 644645.

12 NICHOLS, R. Polyuria and Polydipsia Veterinary Clinics of North America: Small Animal Practice, v. 31, n. 5, p. 833, 2001. 
13 POLZIN, D. J.; OSBORNE, C. A. Dietary Management of Canine Renal Failure. In: BREITSCHWERDT, E.B. Nephrology and urology 1 ed. New York: Churchill Livingstone, 1986. p. 151176.

14 POLZIN, D. J. et al. Chronic renal failure. In: ETTINGER, S. J.; FELDMAN, E. C. Textbook of veterinary internal medicine. 4. ed. Philadelphia: W.B. Saunders, 2000. v. 2, p. 1634-1662.

15 SENIOR, D. F. Management of chronic renal failure in the dog. In: THE COMPENDIUM collection, Treaton, NJ: Veterinary Learning System, 1994.

16 ROSS, L. Hypertension and chronic renal failure. Seminars in Veterinary Medicine and Surgery (small animal), v. 7, n. 3, p. 221-226, 1992.

17 FELDMAN, E. C. Disorders of the parathyroid glands. In: ETTINGER, S. J.; FELDMAN, E. C. Textbook of veterinary internal medicine. 4 ed. Philadelphia: W. B.Saunders, 1995. p. 1437-1461.

18 NAGODE, L. A. Renal secondary hyperparathyroidism. In: ANNUAL MEETING OF SOCIETY FOR COMPARATIVE ENDOCRINOLOGY, 4, Washington, D. C... [s. n.\}, 1990. Proceedings... Washington, D.C., 1990. p. 17-26.

19 SLATOPOLSKY, E The role of calcium, phosphorus and vitamina $\mathrm{D}$ metabolism in the development of secondary hyperparathyroidism Nephrol Dial Transplant n. 13, supplement 3, p. 3-8, 1998.

20 MAHONEY, C. A.; ARIEFF, A. I. Central and Peripheral nervous system effects of chronic renal failure. Kidney International, v. 24, p. 170-177, 1983.

21 KOGIKA, M. M. Avaliação do cálcio sérico ionizado em cães sadios e em cães com Insuficiência Renal Crônica e acidose metabólica. 2003. $134 \mathrm{f}$ Tese (Livre Docência Clínica Veterinária) - Faculdade de Medicina Veterinária e Zootecnia, Universidade de São Paulo, São Paulo, 2003.

22 SENIOR, D. F. Doenças do sistema urinário. In: DUNN, J. K. Tratado de medicina de pequenos animais. 1 ed. São Paulo: Rocca, 2001. p. 914-622.

23 RICHARDS, M. A.; HOE, C. M. A long- term study of renal disease in the dog. The veterinary records, v. 80, n. 22, 1967

24 VADEN, S. L; LEVINE, J.; BREITSWERDT, E. B. A retrospective Case-control of acute renal failure in 99 dogs. Journal Veterinary Internal Medicine, v. 11, n. 2, p. 58-64, 1997.

25 SAMPAIO, I. B. M. Estatística descritiva básica. In: Estatistica aplicada a experimentação animal. $1 \mathrm{ed}$. Belo Horizonte: Fundação de Ensino e Pesquisa em Medicina Veterinária e Zootecnia, 1998. p. 14-19.

$26 \mathrm{LULICH}$, J. P. et al. Feline renal failure: questions, answers, questions. Compendium on Continuing Education of the Practicing Veterinarian v. 14, p. $127-152,1992$.
27 DAVENPORT, D. J.; DI BARTOLA, S. P.; CHEW, D. J. Familial Renal Disease in the Dog and Cat. In: BREITSCHWERDT, E. B. Nephrology and urology. 1 ed. New York: Churchill Livingstone, 1986. p. 137150.

28 KRAWIEC, D. R. Managing gastrointestinal complications of uremia. Veterinary Clinics of North America: Small Animal Practice, v. 26, n. 6, 1996.

29 OSBORNE, C. A. et al. A clinician's analysis of urinalysis. In: OSBORNE, C. A.; FINCO, D. R. Canine and feline nephrology and urology. Philadelphia: Williams \& Wilkins, 1995. p. 136-205.

30 CHEW, D. J.; DIBARTOLA, S. P. Diagnóstico e Fisiopatologia da Moléstia Renal. In: ETTINGER, S. J. Tratado de medicina interna. 3 ed. São Paulo: Manole, 1992. p. $1975-2046$

31 GRAUER, G. F. Alllevaiting Clinical Signs and Slowing Progression of Chronic Renal Failure. In: NORTH AMERICAN VETERINARY, CONFERENCE, Orlando, Florida, 1994. Proceedings... [S. I.: s. n.\}, 1994. p. $15-20$

32 KING, L. G. et al. Anemia of chronic Renal Failure in dogs, Journal of Veterinary Internal Medicine, $v$. 6, n. 5, 1992

33 COWGILL, L. D. Use of recombinant human erythropoietin for management of anemia in dogs and cats with renal failure JAVMA, v. 212, n. 4, p. 521-528, 1998.

34 PETRITES-MURPHY, M. B. et al. Role of parathyroid hormone in the anaemia of chronic renal dysfunction in dogs. American Journal of Veterinary Research, v. 50, p. 1988-1905, 1989.

35 CENTER, S. A. Fisiopatologia e diagnóstico laboratorial das moléstias hepáticas In: ETTINGER, S. J. Tratado de medicina interna. 3 ed. São Paulo: Manole, 1992. $p$

36 KRUGER, J. M. et al. Hypercalcemia and Renal Failure. Vet. Clin. North Amer., v. 26, n. 6, p. $1417-$ 1445, 1996.

37 CHEW, D. J.; NAGODE, L. A. Renal secondary hyperparathyroidism. In: ANNUAL MEETING OF SOCIETY FOR COMPARATIVE ENDOCRINOLOGY, 4., Washington, D. C., 1990. Proceedings... Washington, D. C.: [s. n.\}, 1990. p. 17-26.

38 NASSAR, P. L. Avaliação da concentração sérica de paratormônio intacto ( $\mathrm{PTHi}$ ), pelo método imunoflurométrico, em cães hígidos e cães com insuficiência renal crônica em hiperazotemia. 2000. 93 f. Dissertação (Mestrado em Clínica Veterinária) Faculdade de Medicina Veterinária e Zootecnia, Universidade de São Paulo, São Paulo, 2000.

39 JOCOBS, R. M.; LIMSDEN, J. H.; TAYLOR, J. A Canine and Feline Reference Values In: BONAGURA J. H. Kirk's current veterinary therapy. 13 ed. Philadelphia: Saunder, 2000. p. 1213. 
40 YAPRÉ, W.; FORRESTER, S. D. Renal Secondary Hyperparathyroidism: Pathophysiology, Diagnosis and Treatment. Compendium on Continuing Education fot the Practing Veterinarian, v. 16, n 2, p. 173-177, 180-181, 1994.

41 MARKS, S. L.; TABOADA, J. Hypernatremia and Hypertonic Sindromes. Veterinary Clinics of North American Small Animals Pract. v. 28, n. 3, p. 533543, 1998.

42 PHILLIPS, S. L.; POLZIN, D. Clinical disorders of potassium homeostasis Veterinary Clinics of North America: Small Animal Practice, v. 28, n. 3, p. 545564, 1998.

43 FELDMAN, E. F. Moléstias de glandulas adrenais. In: ETTINGER, S. J. Tratado de medicina interna. 3 ed. São Paulo: Manole, 1992. p. 1801.

44 WALTER, P. A. et al. Ultrasonography evalution of renal parenchymal diseases in dogs: 32 cases (19811986) JAVMA, v. 191, n. 8, p. 999-1007, 1987. 